\title{
Tactics Supporting the Strategies in Today's World
}

\author{
Alexandru Trifu \\ University, Petre Andrei of Iasi, Romania \\ alexandru.trifu@gmail.com
}

\begin{abstract}
The complexity, the variety and the permanent dynamism of today's world (including economic domain) involve a continue flexibility and folding of the enterprise mission to these changing realities. The diagnosis of a firm's activitiy represents the starting point in designing, funding and implementation of strategic-tactical solutions, in order to improve the general activity and the viability and economic-financial and managerial effectiveness of the firm (company, organization). In the present analysis we are focused exactly on the duality or the binomial strategy-tactics, because if the strategy means the hard of the activity, viability and sustainability of an entity and, even, of a country, tactics are viewed as the soft moves, instruments and manoeuvres, in order to help strategy to overpass each stage in order to reach the desired goal or goals (ends). The tactics have to be aligned to and compatible with the chosen and approved strategies. The case of practise is from higher education domain, with the completition strategy-tactics within an university entity. As in each case of business activity, the final goal is to win, to gain profit and to sale safety on the waves of globalization and changing world.
\end{abstract}

Keywords: Strategy, tactics, manoeuvres, determinants, crisis, profit

\section{Introduction}

\section{Defining the terms}

Strategy term: provine from the Greek word "strategos", with the initial meaning of that of part of the military art which was dealing with preparing, planning and conducting of the military operations ( DEX Dictionary, Wikipedia). Any strategy which is dorita to be viable, must include so called key-factors, such as: action plan, strategem, appropriate behavior, position and perspective.

The tactics: include " all the means and processes necessary to achieve a goal" (DEX Dictionary). That is, they mean the indispensable elerments of implementing any strategy. So, the tactics are to support the strategy. Moreover, in terms of temporal, very important is to delineate the two terms:

-strategies are designed for medium and long term.

-tactics are specific actions with expected short-term effects.

Very necessary this dichotomy, the precise understanding of their significance, because in common language the two terms are interchangeable, usually using only the notion of strategy. At the same time, the strategy is the general plan of action, the reinforcement of ideatic construction. On ther other hand, the tactics are the qualitative component, showing concrete "how to do", shaping and finalizing of the chosen strategy, but also the decision taken in any situation occured in the progress of the activity.

The Binomial of the firms' functioning:strategy-tactics: There it is, in a temporal ongoing, the main conceptions regarding the strategy:trategia 1 :

Chandler (1962) ${ }^{2}$ defines the strategy as being the long-term determining of goals and objectivesof an organisation and the allocation of needed resources to achieve them. Andrews (1971) ${ }^{3}$ sees the strategy as the system of goals and objectives, of policies and plans in order to achieve these goals, such as to contribute

\footnotetext{
${ }^{1}$ See also Salceanu, C. (2005)-Management strategic. Concepte si studii de caz, Ed. Vasiliana '98, Iasi, ch. 1.1

2 Istocescu, A. (2005) -Strategia si managementul strategic al organizatiei, Ed. ASE, Bucuresti, p.64.

3 Istocescu, A.-op. cit., p.98.
} 
defining the domain of activity, or the type of business that the firm wants to become. Hofer şi Schendel ${ }^{4}$ (1978) : strategy means a mode of understanding the evolution of the current and expected development of the resources and interaction with the environment, indicating how organization will achieve its objectives. Quinn (1980) ${ }^{5}$ : a model or a plan which integrates in a coherent whole the major organization goals, policies and steps of the activity. On the other hand, Ansoff 6 treats synergy as common axis of the organization's activities and of the outputs/markets which the entity carries on or plans to do on the future. The synergy means how to increase the productive capacity of each component of the microeconomic system of a firm, by structuring a sound and effective interaction with the other components. We consider that in this place and moment the core of the addressed problem intervenes, meaning that there are, at firms (organization) level, strategies on different structural and existential components, such as: development strategies, strategy of market scale and product scope, strategies of investments, R \& D strategies, commercial strategies, personal strategies, internationalization strategies. These are co-ordinates to achieve the major goals of the entities and hence the active interaction occurs also between the tactics elements for each strategy separately ${ }^{7}$. Even the definitions are quite different, some elements are the same in each of these statements: goals to be reached, medium and long term for the realizare and an allocation process of the resources in order to realize these goals. The most recent definitions of strategy are underlined by Henry Mintzberg, regarding it as a perception, designating a predetermined course of action, in order to solve a given situation,

or viewed as a model that sets a pattern of consistent actions throughout behavioural level, or as a positioning of the firm, what lies in the means of identification of the place the entity has in its environment, i.e. on the market.

\section{Harvard Business School}

Most authors and experts in the field acknowledge the Harvard Business School as a starting point of the conceptual definition of the term strategy. The Treaty of Economics, published in 1965 by Learned, Cristensen, Andrews and Guth, is the remarkable synthesis of the classic business strategy definition, meaning that the basic principle of any analysis requires the harmonious combination of the following:

a. Strengths and weaknesses and

b. Environmental opportunities and threats

These four relevant elements have shaped the SWOT analysis with the above meanings. Thus, any firm (company, organization) can be assessed in terms of achieving the major (strategic) objectives through performance management, and constantly confronting the business or natural environment. Thus, the strategy is, at the same time, a way of placing the organization in what is called "environment", be it business or natural environment. Moreover, the strategy must proportion the internal environment of the organization with the external environment, and the possibility of developing relationships or confrontations in terms of competition or "economic games". We also owe Mintzberg the attempt of providing a complete picture of the strategy, after analysing a number of approx. 1500 case studies and several schools of management thought. The defining features of the strategy regard the following issues 8 :

- The objectives are the motivational and operational grounds of the strategy, their quality is crucial to the future performance of the organization;

- The strategy regards future periods in the company's life, usually 3-5 years. Hence the high degree of risk and uncertainty that it is being associated, along with all the consequences of the operational process;

- The content of the strategy comes down to the essential elements, focusing on the major developments of the company, whether they show changes in comparison to the previous period or not;

- The strategy is based on the correlative approach of the organization and its environment. The

\footnotetext{
${ }^{4}$ Istocescu, A.-op. cit., p. 98.

${ }^{5}$ Istocescu, A. -op. cit., p.126.

${ }^{6}$ Istocescu, A. -op.cit., p. 116.

${ }^{7}$ Deaconu, Alecxandrina (2003)-Economie d'entreprise, ASE Publishers, Bucuresti, p. 165-181.

8 Nicolescu, Ovidiu, (coord.) (1998)- Strategii manageriale de firmă, Editura Economică, Bucuresti, p.37
} 
strategy largely regards achieving an effective interface between the company and the environment, reflected in the organization's performance;

- Gaining competitive advantage is the main aim of elaborating the strategy and the most important criterion for assessing its quality.

However, while trying to enter a particular market or to stay in it, by using appropriate strategies, the entity uses different techniques, specific activities, manoeuvres, which support the company (organization) and the chosen strategy at any moment of its productive existence: we refer to business tactics. Specifically, business tactics regard the provided product or service, means of advertising and branding, distribution channels everything the price policy involves - when competing on a specific market.

\section{Endogenous determinants of the strategies}

In order to understand the importance of the relationship of supporting and correcting the tactics for accomplishing the proposed strategies, let us see which the determinants are influencing the strategies based on which the appropriate tactics need to be shaped are. We shall start with the internal (endogenous) determinants, which are called internal because they occur within the company ${ }^{9}$ :

- Ownership - in terms of the economic power held and the share in the company's capital, the interest in the specific activity, etc.

- The size and complexity of the firm - the interest falls on the extent and degree of diversification of the actions undertaken, hence the greater or lesser complexity of the strategies adopted.

- Human resources - the main determinant factor of production, where the interest falls on the size and quality of the staff.

- Technical and informational potential - each component of the overall strategy, aiming at achieving profit and competitiveness, is designed and implemented according to the diverse and updated information held by the firm. Holding office equipment, modern IT technologies, as well as installations, machinery and new equipment, as appropriate, is essential in order to ensure the quality of production or service providing activities, as well as the corresponding outputs.

- Organizational culture - Through the way, it is supported and continuously adapted to the stages and challenges the organization is facing.

As a corollary, the action of the tactical elements specific to company strategies is strictly developed according to the economic status of the entity and based on a global managerial model thinking, through the management's view of the business evolution, charisma, the knowledge and skills related to the strategy, the good management of the organization and by making market relations more flexible.

\section{Contextual determinants of the strategy}

The implementation and success of any promoted strategy also requires the ability of the firm's decision makers to exert influence through feedback processes.

- The economic (business) determinant - is the most important because it includes the relationships with the other components of the market.

- The social determinant - envisages the human and community dimension where all the entities act.

- The political determinant - when shaping policies, one must consider not only the free market mechanisms and requirements, but also especially the elements of economic policy, the decisions and regulations that the political element imposes in daily life.

- The legal determinant - legal regulations are mandatory for any company (organization). By knowing the legal dispositions, through the strategy they elaborate, decision makers can exploit the facilities provided by these regulations to a high degree and are able to avoid the "traps" or the negative aspects that may occur.

9 See also Nicolescu, O., Verboncu, I. (1999)-Management, $3^{\text {rd }}$ edition, Economica Publishers, Bucuresti, p. 148-153. 
Speaking about the exogenous determinants, the financial and economic crisis is the most important such determinant in our days ${ }^{10}$. Moreover, the famous economist insists on the tail risks ${ }^{11}$ (debt sustainability, lack of economic growth, loss in competitiveness) which remain and "attack" to the strategy structure of the enterprises involved in such commercial and financial acts. Therefore, the importance given to the sequence of tactics, in order to absorb such distortions and to ensure the straight way to the required ends. As we have underlined in the sub-chapter's title, the importance of tactics is very high, because some so-called specific strategies are functioning in the theory and practice of marketing, particularly, such as differentiation strategies, offensive strategies-guerrilla attack, detour strategy, front strategy-, defensive strategies-active, fix, mobile, counterattack strategies. We think that all these and other of the same kind can be, more appropriate, to be called tactics, supporting the main strategies of the firm, in order to achieve the desired ends.

Now, we want to give an example from the high education sector. A private university (entity), through its Administration Council (Board of Directors) sets, decides the strategy to be followed: to become the most important high education private entity from a region of a country; to include a wide range of faculties and specialities, in order to cope to the demand from the labour force market. As Peter Drucker said ${ }^{12}$, using the marketing function, important is to create a consumer. How to do this in our case? By advertising in diverse media, using "open gates days", the information regarding the performances through discussions from person-to-person (especially from graduates of the respective university) and so on. However, in order to gain all these, tactics occur. The specific departments, or chairs, prepare programs of study, the compulsory and optional disciplines, specific to each specialization involved in. The quality of courses and seminars, in order to attract students, the efficiency of academic research, in order to capture the interest of business environment, not only as sponsors, but collaborators in grants or different contracts. Moreover, the state regulations in the field, the evaluation of the academic and research activities by accredited high education units, are operative discussed, analysed and agreed upon the tactics set by the specialized departments.

\section{Conclusion}

The strategy is not in disgrace in this era, but this one is supported more and more suggestive by the tactics in the "economic games". The binomial to be taken into account, either by the firms (companies, organisations), or by countries, is in our days strategy-tactics, because the challenges of the environment (political and business, especially) and the impact of different determinants, involve that the activity to overpasses each such affect or period of turbulences. From the practice of microeconomics and strategic management, the marketing function (in services domain) or sub-function in business activities drives the tactics, because it deals with launching products or services on the market and with customers, either for increase profit, or to stop for going on a competitor. Even tactic is often used, as term, in sport, we consider that either in business it is better to involve it, because it represents the adequate answer or quick riposte to a specific factor or determinant in a specific stage of the activity. This disturbance has to be avoided only by using firm welldesigned decisions ploys, techniques and better acknowledge of the feedback information or signals. It is important and necessary to use the SWOT analysis in the evaluation of firms (entities), determinant in the understanding of the existence and surfing of the entity on the waves of the dynamic economy of today.

A sound principle to materialize the binomial strategy-tactics was enunciated by Gilbert Clee-former CEO of McKinsey \& Company, principle confirmed especially in the activity of the trans-national companies: buy raw materials from where they cost less, develops production/services where the salaries paid are low and sell the products or services where you can gain the higher possible price. The main END is to satisfy the consumers' needs and to maximize, as possible, the profit. For our example, it is quite different if you want to be the best in the preparation of human capital: attract students eager to learn and to enhance, deal with academicians very well trained and well paid and off the market, the best graduates in their field. The more points you score is better for the enterprise (entity...) and the way you done, it is possible through well-based

\footnotetext{
${ }^{10}$ Roubini, Nouriel, Mihm, St. (2010)-Crisis Economics. A Crash Course in the Future of Finance, Penguin Press, New York, ch. 8-10.

${ }^{11}$ Roubini, Nouriel (2013)-Nouriel at Davos: Global Tail Risk Remain, www.economonitor.com, retrieved $1^{\text {st }}$ of April 2013.

${ }^{12}$ Drucker, P. (1954)-The Practice of Management, Harper \& Row Publishers, New York, part one.
} 
sequenced tactics. We consider that if a strategy is good and the tactics sound, there are better chances for sustainability, depreciation of the shocks in the current activity and better comparative advantages on the market. To play or counter-play successfully, based on competition rules (including the famous Porter's five forces of impact), mean to play different that the others, a higher level than to play better than the others and these results are due to skilfully implemented tactics.

\section{References}

Ansoff, I. (1990). Strategie du developpement de l'entreprise, Les Editions d'Organisation, Paris.

Chandler, J. r. \& Alfred, D. (1962). Strategy and Structure: Chapters in the History of the Industrial Enterprise, MIT Press.

Deaconu, A. (2003). Economie d'entreprise, ASE Publishers, Bucuresti.

Drucker, P. (1954). The Practice of Management, Harper \& Row Publishers, New York.

Istocescu, A. (2005). Strategia si managementul strategic al intreprinderii, ASE Publishers, Bucuresti.

Nicolescu, O. (coord.) (1998). Strategii manaheriale de firma, Economica Publishers, Bucuresti.

Nicolescu, O. \& Verboncu, I. (1999). Management, $3^{\text {rd }}$ edition, Economica Publishers, Bucuresti.

Porter, M. E. (2008). The Five Competitive Forces That Shape Strategy, Harvard Business Review, January.

Roubini, N. M. S. (2010). Crisis Economics. A Crash Course in the Future of Finance, Penguin Press, New York.

Roubini, N. (2013). Nouriel at Davos: Global Tail Risks Remain, www.economonitor.com. 